\title{
PREOCUPACIONES REINANTES ACERCA DE LA LOCURA *
}

\section{José Esquerdo}

\section{Señores:}

Cuando tuve la inmerecida honra de ser invitado por los dignísimos Presidente y Secretario primero de este ilustre Ateneo para que inaugurase las Conferencias correspondientes al período académico actual, acepté sin ceremoniosas escusas, á pesar de que me abrumaban la grandeza de la distincion y el recuerdo de los eminentes profesores y sábios maestros, á quienes cncomendásteis igual tarea científica el próximo pasado curso, y ¿sabeis por qué? porque creí que tratábais de ofrecer vuestro valioso tributo á la enseñanza libre, en manera alguna de honrar con el homenaje de vuestra consideración y afecto mi humilde personalidad.

Conste, pues, que yo acepté vuestra inmerecida distincion, considerándome en igual caso que cl sacerdote á quien una penitente, encontrándo'e casualmente en el átrio del templo, le entrega la ofrenda para que la lleve al altar de su devoción. (Bien, bien.)

Yo recibo con gratitud profunda vuestro riquísimo presente, pero es

* Conferencia dada en el Ateneo de Internos de la Facultad de Medicina de Madrid, el día 5 de diciembre de 1878, por el doctor don José Esquerdo, médico del Hospital general de Madrid, fundador y Director-propietario del Manicomio situado en el término de Carabanchel Alto (tomada taquigráficamente por el señor Obispo). Publicaciones del Ateneo de Internos, Madrid, 1878. 
para depositarlo en el altar de la enseñanza libre, diosa de nuestra redención. (Aplausos.)

Como en esta Sociedad, el ingenio y la galantería son solariegos, sin duda para abrillantar la Conferencia me impusísteis la condicion de que disertase sobre enfermedades mentales; csto es, sobre lo mismo que yo hubiera escogido; ¡siempre tan discretos! En otro tiempo me invitásteis para que hablara del delirio; más tarde sobre causas morales de la locura; hoy sobre preocupaciones reinantes accrca de la misma; me sujetais sí, pero con dulces cadenas, con las cadenas de mi vocacion, análogas ó idénticas á las que unen al padre con el hijo, al esposo con la esposa; jlas únicas cadenas que $\mathrm{cl}$ hombre libre besa! ¡Las únicas cadenas que el ciudadano honrado no forcejea por romper jamás! (Aplausos.)

Señores: el campo de la frenopatía es tan feráz en preocupaciones, que apenas hallareis espacio libre de ellas en donde hundir vuestra planta, y á la manera como las enfermedades imaginarias nos atormentan, cual si fueran dolencias reales, así las preocupaciones inducen á obrar cual si fuesen conceptos fundados. Interesa, pues, combatir, estirpar de cuajo, las preocupaciones reinantes en enfermedades mentales, para despues sembrar la buena doctrina; como veis, el procedimiento es análogo al que sigue el labrador que desea obtener una buena cosecha; primero remueve la tierra, arranca la cizaña, despues sepulta la scmilla; ayudadme, yo os lo ruego, á disipar de la conciencia de los magistrados, las preocupaciones que la oscurecen; iluminadla con las opiniones reinantes en nuestra ciencia; la reforma urje porque sin ella no hay administración de justicia posible. (Aprobación.)

La primera y más trascendental de todas las preocupaciones, por cuanto es origen de casi todas ellas, la que encierra en sí la sustancialidad de las más; es el considerar la locura como una enfermedad del alma, cuando en realidad significa un conjunto de padecimientos del cuerpo que afectan directa ó reflejamente al cerebro.

Señores: toda enfermedad mental es un padecimiento del cuerpo, tan ordinario, tan orgánico como lo pueda ser una blenorragia ó una pulmonía, ni más ni ménos, ni ménos ni más; cuantas diferencias separan las enfermedades mentales de las restantes que afligen nuestro cuerpo, otras tantas existen y son motivo de distinción entre las correspondientes á diferentes grupos; cuantas analogías se advierten en los padecimientos comprendidos en una clase, otras tantas hallareis entre la multitud de variedades mentales; distínguense los padecimientos propios de un aparato de los que afectan á otro conjunto de órganos, por una série de circunstancias que concurren también á la distincion de las enfermedades mentales, de las que conocemos vulgarmente con el nombre de ordinarias; y toda la série de atributos anteriores, actuales y posteriores, comunes á los diferentes grupos que abarca la patología médico-quirúrgica los hallareis en la cnajenacion mental, como que la frenopatía no es más que una rama de la medicina. En efecto, tiene 
la locura, como el resto de las enfermedades, su etiología, su patogenia, su sintomatología, su patocronía, sus terminaciones y tratamientos.

¿En virtud de qué distinguimos los males propios de un grupo de los correspondientes á otro, en un sentido sintomatológico, sino por la perturbacion ocurrida en las funciones peculiares del aparato afecto? Las enfermedades del tubo gastro-intestinal se revelan por inapetencia, sed, dispepsia, vómitos, diarrea, etc., ó lo que es lo mismo, alteracion de las funciones digestivas.

Las del aparato pulmonar por fatiga, tos, espectoracion, ó sea trastorno de las funciones respiratorias.

Las del aparato cerebral, con delirio, alucinaciones, convulsiones, impulsiones insólitas, ó sea con perversiones psicomotrices. Resulta, pues, que siempre, constantemente, allí donde se localiza el mal, surje el trastorno, brota la perturbación.

¿Es la mana, de cuya superficie mana ese precioso néctar que nos alimenta durante la infancia; como de la superficie de la tierra, brota la fuente que cubre de verdor la pradera? pues se alterará el jugo lácteo.

¿Es el hígado en cuyo profundo parénquima se confecciona la bílis; como en el interior de la tierra se fabrica el hierro? pues se alterará el jugo biliar. ¿Es el cerebro en cuya altura orgánica se produce el pensamiento; como en las elevadas regiones de la atmósfera se fulmina el rayo? pues se pervertirá el fluido psíquico. Siempre, ya lo veis, cambian las condiciones del producto cuya elaboración le está encomendada.

Además, es condicion inherente á la sinergia que preside nuestro organismo, que los males extiendan su influencia más allá de su region; así notareis que un enfermo del aparato respiratorio digiere mal, como otro del aparato digestivo desempeña irregularmente las funciones respiratorias, y de igual suerte encontrareis pacientes á quienes aqueja una enfermedad pulmonal, gastro-intestinal ó febril, propiamente dicha, cuyas facultades mentales están pervertidas. La misma influencia que todos estos padecimientos ejercen sobre las funciones mentales, tiene la enajenacion para con las funciones digestivas, nutritivas, respiratorias, circulatorias, etc., las cuales trastorna, y trastorna profundamente; ¿qué son sino los síntomas somáticos, cuyo valor inmenso decide del diagnóstico en los casos dudosos? Todo ello no revela mas que el cumplimiento de una ley, la misma que del conjunto de unos órganos hizo un aparato, y del conjunto de los aparatos hizo al hombre.

Se me dirá, señores, y yo lo acepto de buen grado, que los síntomas propios de las enfermedades mentales no son como los del aparato digestivo, respiratorio, circulatorio, etc., que no pasma ni suspende al hombre, que un sugeto que ayer respiraba bien, hoy esté disnéico; otro que ayer digeria las sustancias más refractarias á los jugos gastro-intestinales, hoy soporte con dolor el alimento más ligero; ¿pero maravilla y enajena observar que hoy se proclama opulento Creso el que ayer lloraba su mísera indigencia; que un 
padre amantísimo de sus hijos atente bárbara y cruelmente contra la vida de los mismos; que un sacerdote, siempre modelo de castidad, se lance como feroz hiena sobre su presa violando la virginidad de recatada doncella; que. el tierno esposo de virtuosa y ejemplar mujer, la mutile bárbara y villanamente? Es cierto scñores que todo es conmovedor, maravilloso, sorprendente, como grande, sublime y sorprendente es el funcionar del cerebro. (Aplausos.)

$N$ ada en la naturaleza iguala en magnitud, en esplendor, en maravillosidad al cerebro. Si al haccr Dios al hombre el último dia de la creacion quiso revelarnos que éste es su obra más perfecta; aunque lo callen las Sagradas Escrituras, debió fabricar el cerebro en la última hora del último dia, porque es el órgano más acabado de la más perfecta criatura. (Bravo, bien.)

No es el sol el astro orígen de la luz, sino el cerebro, sin cuyas emanaciones siguiéramos sumidos en perpétuas tinieblas; aquél, es verdad que. alumbra el firmamento, pero éste ilumina la humanidad, que es el bello firmamento en que se extasia Dios. (Aplausos.)

El cerebro recibió de la Providencia el universo, para que se esplayara, y él devuelve á esa Providencia un mundo mayor, si cabe, con sus ciencias. con sus artes y con sus industrias en cumplimiento del destino que le impone la divinidad. (Grandes y prolongados aplausos.) Que más, señores, yo creo que si Dios, á pesar de su infinita prevision, hubiese olvidado crear el sol que nos alumbra, el hombre hubiera escalado los cielos y suspendido de la divinidad la luz eléctrica, sol de su intención para alumbrar los diversos mundos. (Grandes aplausos.)

Señores, acongoja el ánimo considerar que en punto á causas son vulgo aún los hombres más ilustrados: en ese confesionario en donde creyentes é impíos depositan sus flaquezas, la consulta médica, se oyen las preocupaciones más inconcebibles; si el cliente procede de la clase obrera, atribuye la enajenación de su deudo á una diabólica confeccion culinaria, como, por ejemplo, caldo de gallina negra con sangre del flujo ménstruo; y si de la clase acomodada, al producto químico obtenido por las cavilaciones del sábio; y sin embargo, tiempo há que los médicos frenópatas todos han proclamado y difundido, que no hay sustancia natural ni artificial capaz de determinar una enfermedad de las comprendidas en la locura.

Las personas, más cultas llevadas de las preocupaciones infundidas por las escuelas teológica y metafísica, felizmente sepultadas en el descrédito, se afana en buscar una pasion que haya provocado el trastorno moral, y se fijan en el juego natural y comedido de este ó el otro afecto, pasando por cima de causas tan poderosas como una herida en la cabeza seguida de conmoción profunda: ¡cuántos hechos de observacion propia pudiera citaros en que la causa productora de la enajenacion fué un traumatismo, esto es, un agente mecánico, y sin embargo, se referia á leves é insignificantes disturbios domésticos!

En regiones superiores domina la preocupación de asignar á cada caso 
una sola causa, y en otras, que ya penetran en los confines médicos, se refieren como causas una série de hechos que revelan otros tantos síntomas de locura, como la irritabilidad del carácter, matrimonios desiguales, abusos genésicos, alcohólicos, quebrantos de fortuna por empresas arriesgadas, etc., etc., y mas de una vez, investigando escrupulosamente los hechos, me he convencido de que el cambio de carácter, los abusos genésicos, empresas temerarias, etc., habian tenido lugar despues de la invasion, y consiguientemente eran manifestaciones de la locura, no causas de ella.

La enajenacion mental, como acredita la experiencia de todos los dias, procede, unas veces de causas morales, otras de causas llamadas materiales, y un número no escaso, del concurso de estos y aquellos agentes. Entre las causas materiales, todos los grupos tienen su representacion; así se vé, entre las mecánicas, un sablazo en la cabeza, la caida desde lo alto de un andamio, etc.; entre las físicas, una insolación; entre las químicas, las bebidas alcohólicas, y entre las fisiológicas, la edad, sexo, temperamento mental, etc., no faltando, por fin, las causas morbosas, por cuanto la epilepsía, histerismo, pelagra, herpes, reuma y otras enfermedades, provocan la enajenación mental.

Mas nótese, señores, que si bien al incesante estruendo de encontradas pasiones se enajena el cerebro, que si porfiados trabajos intelectuales vejan el entendimiento y le sumen en la demencia, también esas pasiones y ese trabajo mental desmedido socavan la integridad de otros aparatos y provocan enfermedades reputadas por ordinaria. ¿Quién no recuerda una lesion orgánica del corazón causada por el terror? ¿Quién no ha visto surgir el cáncer del estómago bajo la influencia de pasiones morales deprimentes? ¿Quién no ha notado la aparición de gastrálgias á consecuencia de meditaciones profundas y repetidas? ¿Quién no llora la pérdida de una amiga devorada por la tisis á consecuencia de un amor burlado? Esto dice, á todo entendimiento claro, que las enfermedades mentales tienen sus causas morales y materiales, como acontece con los padecimientos ordinarios. Que los agentes morales provocan indistintamente afectos ordinario ó enajenaciones.

Por último, se me dirá que las causas morales inducen con preferencia á enfermedades mentales; observacion exacta, pero que no invalida mi aserto, ni contradice lo que el buen sentido y la experiencia de consuno abonan; tal es el de afectar los agentes aquellos órganos con quienes primero y directamente se ponen en contacto; así las trasgresiones en la comida causan males del aparato digestivo, las trasgresiones en la respiración del aparato pulmonar, como un esfuerzo producirá una lesion en los músculos, ó articulaciones, ó huesos, ¿por qué? porque enferman á virtud del choque, y éste es antes que el contragolpe.

Señores, hay una preocupacion funesta, trascendental y de consecuencias espantosas; tal considero la de no reputar por loco más que á los pobres maniacos, siendo así que ni son estos los más graves, ni ofrecen mayor duracion, ni presentan más dificultades al tratamiento, ni tienen las terminaciones 
más fatales, ni motivan esos ruidosos procesos que llegan á interesar la opinión pública. Para el vulgo, hé aquí el único enajenado: el hombre que se agita sin cesar de uno á otro lado, paseándose por el interior de una habitacion, ó corriendo por las calles cual fiera enjaulada ó perseguida por los cazadores; el que habla en alta voz y espantosa locuacidad; el que grita, injuria, maltrata, destruye, confunde las personas, cambia los lugares y trueca las cosas, sin considerar que la enfermedad arma á este desgraciado, pero le venda los ojos; el loco verdaderamente temible, el que causas esos atentados que hacen extremecer la conciencia humana, es el monomaniaco, el de locura parcial, el que. está igualmente armado como aquel, pero libre la vista y con la inteligencia al servicio de aviesa impulsión.

Tiempo há que los médicos frenópatas multiplican sus esfuerzos para conseguir que la monomanía, esto es, la locura parcial, la locura con delirio circunscrito, ó sin él, se abra paso en el foro; y á pesar de tan titánicos esfuerzos, no hemos logrado que la luz de los mentalistas penctre en la conciencia de los magistrados. (Sensacion.)

¿Sabeis en qué consiste tan raro fenómeno? En que no tienen clínica de enfermedades mentales; si yo fuese á escojer entre un curso teórico de frenopatía, y la estancia de los magistrados por espacio de los ó tres meses en un manicomio, optaria por este último extremo, seguro de alcanzar la reforma apetecida.

Esquirol, príncipe de los mentalistas, que habia escrito contra las monomanías, no pudiendo comprender una «enajenacion mental que se manifestase solamente en algunos actos del alma sin alteracion aparente de los otros», esto es, un conjunto de razon y de locura, de órden y de desórden, de claridad y de tinieblas; el sábio Esquirol, que habia escrito: «¿Pero existen verdaderamente manías en las que el enfermo conserva integra su inteligencia, al paso que se abandona á las acciones más abominables? ¿Hay un estado patológico en que el bombre se sienta irresistiblemente arrastrado á ejecutar actos que su conciencia reprueba? Yo no lo creo.» Tal era, en efecto, su doctrina en 1818; pero desde dicha memorable fecha, atento siempre á la observacion de los fenómenos, cambia de opinion, porque observa multitud de enajenaciones sin delirio, y como acontece á los hombres de buena fé, somete su doctrina á la autoridad de los hechos. Las más bellas y gloriosas páginas de Esquirol, las que han elevado su memoria sobre el nivel de los más eminentes mentalistas, están inspiradas por un sentimiento de contricción. Muy luego de abrazar su nueva doctrina, se apresura á difundirla por luminosos escritos, encabezándolos con esta hermosa retractacion: Me rindo ante la evidencia de los hechos.

Los que conocemos ligeramente los resortes que mueven la mente humana, dudamos obtener un cambio de opiniones del sábio que, abroquelado por formidable cota de malla, un sistema, no deja punto por dónde pueda penetrar argumento alguno extraño á sus creencias; que encastillado en lo 
alto de una escuela, desoye las voces de las huestes enemigas. La pública confesion de Esquirol es un acto de heroismo que le honra sobremanera. Pero cambiar de opinion cuando está interesada una reputación científica, laboriosamente adquirida, cuando no se presume de haber hecho estudios profundos acerca de la materia, es acto felizmente para la humanidad que no implica sacrificio alguno; por eso, señores, yo me lisongeo de una próxima victoria, y no lo dudeis, la obtendremos si acertamos á exponer con claridad los hechos.

Descarto cuidadosamente todos los argumentos técnicos porque me dirijo á la conciencia de los profanos; renuncio al riquísimo arsenal de formidables armas, con que me brinda la fisiología del sistema nervioso, ilustrada por los modernos trabajos de Luys, Poincaré, David Ferrier, Carpenter, Meynert y Schiff, porque pretendo atraer á nuestras doctrinas el entendimiento y corazon de los jurisconsultos; ellos, como nosotros, están interesados en el triunfo de la verdad, sin la cual no hay administracion de justicia posible; ellos como nosotros tienen por sagrados los fueros de la humanidad doliente, y sin esa luz que los ilumine, los hollarán muy á su pesar; ellos, por fin, mejor que nosotros, saben que la ejemplaridad de un castigo no ejerce influencia alguna sobre la conciencia del enajenado, y que el sacrificio de una víctima inocente, inmolada por la ignorancia de los tiempos y la preocupación de los hombres, despierta en las conciencias honradas un grito de maldición que conmueve la firmeza, y vuelca el prestigio de la magistratura. (Bien, bien.)

Señores, es en ocasiones tan reducido el círculo de la perturbación mental que pasa desapercibido en una primera y segunda esploracion, como sucede á menudo con la insensibilidad, ó anestesia parcial de la piel sino se acierta á colocar el dedo sobre la region afecta. En otras el disimulo del enajenado es tal, que se requiere una inteligencia avezada á estas esploraciones, un hombre práctico, en fin, para evidenciar la locura.

Que esta ofrece remisiones é intermitencias lúcidas, es verdad del dominio público, y consiguientemente, los más prolijos exámenes no descubrirán entonces perturbación alguna.

Los médicos frenópatas, todos, saben cuán frecuentemente encauza la razon un hecho que ha conmovido la conciencia del enajenado, siguiendo á este un período de lucidez, más ó ménos duradero, y en ocasiones la misma curacion; Esquirol y Bonunci así lo proclaman. De lo dicho, pues, se infiere que el loco no lo es por regla general en toda la extension de su inteligencia, sentimientos é instintos; que no está trastornado á todas horas ni todos los dias, y, por último, que su perturbacion afectiva ó intelectual, puede ser tan reducida que no la descubra el profano y aún el mismo médico, sino tiene práctica frenopática.

Vengamos á la preocupacion más dificil de desarraigar, porque se escuda tras de una psicología metafísica, que repugna la multiplicidad de órganos 
mentales y el padecimiento de uno ó más de ellos, con la integridad del resto, ó sea de todos los demás.

Es ley del entendimiento rechazar lo que implica contradicción: ínterin subsista la novela psicológica que hacen pasar por fisiología mental, forcejearemos en vano para que acepten nuestra doctrina los profanos, y especialmente los magistrados. Hagámosles ver que esa psicología metafísica es tan postiza, aun para ellos mismos, que no arraiga en su conciencia; demostrémosles que tienen otra fisiología empírica, más conforme con la verdad, más positiva; como que está fundada en la experiencia.

Todo el mundo que haya fijado su atención en las circunstancias fisiológicas mentales propias ó de los demás, habrá notado que es la inteligencia, distinta de los sentimientos ó instintos; que el nivel orgánico de esta y aquellos, varian segun los individuos; más aún, que dentro de la misma inteligencia y dentro de los afectos, hay facultades, sentimientos é instintos predominantes.

No otra cosa significan las frases: Fulano es todo cabeza, esto es, inteligencia; Mengano todo corazon, esto es, afectos.

Contrayéndonos á la inteligencia, distinguimos al amigo que tiene grande aptitud para la síntesis, y menguada para el análisis, ó lo que es lo mismo: aquél predominio de las facultades reflectivas, éste de las perspectivas; y las mismas apreciaciones hace el vulgo cuando dice: éste tiene buen golpe de vista, aquél es muy minucioso.

Pasando ahora desde la inteligencia á los afectos, nótese que distinguimos el carácter de los hombres porque son valientes, cobardes, generosos, mezquinos, religiosos, impíos, castos, lujuriosos, etc., ó lo que es lo mismo, por el predominio fisiológico y constante de unos sentimientos é instintos sobre los demás.

Dentro del juego funcional de nuestra mente, reconocemos sin violencia la exaltación accidental de un sentimiento, con depresión de la inteligencia.

¿Quién de nosotros no habrá intentado disculpar á un amigo diciendo le cegaron los celos? Luego cabe la exaltación accidental de un sentimiento, el amor, con depresion de la inteligencia.

Resulta, pues, que las facultades intelectuales, los sentimientos é instintos son diferentes, tienen diversas proporciones, y en el ejercicio normal de ellos se advierte que los unos se sobreponen accidentalmente, sin romper esa armonía que constituye la razon.

¡Otra fuera la suerte de la humanidad, si á una gran inteligencia correspondiese un gran carácter moral! ¡Y otra fuera igualmente la suerte de nuestra desgraciada España, si corrieran á la par la inteligencia y los sentimientos! Nuestro infortunio depende de que sobran talentos, si sobrar pudiera este destello de la Divinidad, y faltan caractérez. (Aplausos.)

Pues bien; si esta es nuestra fisiología, cá qué rechazar la única patología que concuerda con ella? Uno es el modo de funcionar normal y morboso del 
hombre, con la única diferencia de que la enfermedad rompe, pulveriza los lazos que unen las diferentes facultades entre sí, y que solo llega á relajar la pasion.

Si médicos y profanos convienen en estas apreciaciones, es porque la vida social representa una vasta y constante clínica que les sirve de enseñanza. Si los jurisconsultos, como los médicos, pasaran á los manicomios y estudiaran las enfermedades mentales, de seguro que llegarian á profesar unas mismas opiniones en punto á hechos bien observados ya por los frenópatas, y que ellos podian comprobar todos los dias. Dispensadme la repeticion; yo no conferiria á hombre alguno las funciones más sublimes dentro del órden social, las de la magistratura, sin asistencia prévia, por espacio de dos ó más meses, á la visita de un manicomio.

Hemos dicho poco há que los hombres ofrecen diversas inclinaciones, pues otras tantas son las monomanías cuya existencia real pugnan por rechazar los magistrados por falta de experiencia; á suplir esta con hechos auténticos observados por distinguidos mentalistas y por mí, se dirigen las observaciones que voy á a referir, contrayéndome únicamente á las monomanías agresivas, por ser las que motivan causas criminales.

Como no pretendo hacer la historia de estas locuras parciales, claro está que no he de remitirme á las causas, génesis, curso, tratamiento, etc., y sí solo á la parte correspondiente de síntomas, á los hechos que han motivado, y á las apariencias; pero notarlo bien, meras apariencias, que los asemejan á crímenes horrendos, pero cuya analogía se disipa á la accion de la inteligencia ilustrada, como se disipa la niebla de los valles á la accion del sol matutinal.

El crímen tiene su fisonomía, como el atentado concebido por el loco tiene su cuadro fenomenal; el diagnóstico diferencial entre ambos compete al médico por la parte técnica del último.

Yo ya sé que se injuria al médico frenópata por haber proclamado la verdad incontrovertible de que cabe la locura sin aberracion de la inteligencia.

Yo no ignoro que se aterra á los ánimos pacatos con la perspectiva de que esas monomanías serán el refugio de los criminales, manto de proteccion de los asesinos; pero ni una ofensa ha sido jamás un argumento, ni el terror quimérico de los cavilosos ha contenido el ánimo viril del hombre de conciencia que se adelanta á proclamar una verdad de todo punto indiscutible.

Importa consignar, porque tanto el crimen como el atentado del loco tiene sus antecedentes, una circunstancia, y es que el erotismo, la supresion de hemorrágias, la conmocion del ánimo por un espectáculo imponente, y la lectura de atentados que por circunstancias particulares han logrado intereses la conciencia pública, figuran frecuentemente en las causas de las monomanías agresivas.

Mas os dije que me contraeria exclusivamente á los hechos, y héme decidido á ello. 
Acababa una madre de experimentar la dolorosa pérdida de su hija. $¡$ Desgracia, señores, que en los transportes de pena del corazon herido acusa inconsecuencia del Creador, porque los padres no deben sobrevivir á sus hijos! (Sensacion.) Cuidaban del cadáver unos hombres; la madre se habia retirado á descansar, dije mal, á llorar, porque una madre no descansa la noche en que pierde un pedazo de su corazon; oye un ruido, y se levanta sobresaltada; acude á la estancia de su hija, y nota que sale un hombre en camisa; llama á la gente, acuden todos, examinan al hombre; al principio creyeron que seria un ladron, pero al verle desnudo casi, y notar su aspecto, dudan, le interrogan, y contesta con frases confusas; se acercan al ataud, examinan el cadáver y notan señales inequívocas de violacion reciente; este infortunado, que ya le podemos llamar así, habia ganado la guardia para realizar ese horrible atentado, y ya en otras ocasiones, segun el exámen retrospectivo de su vida, había consumado el mismo hecho en el cadáver de otras jóvenes. ¿No creeis, señores, sobrada prueba de locura la aberracion inconcebible de alejarse el estro genésico de su natural satisfaccion en el sér vivo, para ir á sumirse en la hediondez de la aterradora muerte? Brierre de Boismont refiere este caso bajo el epígrafe de El amante de la muerte.

Palpitante están aun el proceso del sargento Bertrand que conmovió el corazon de cuantos llegaron á conocerle. Este infortunado acababa de sufrir durante quince dias dolor de cabeza, cuando se sintió impulsado á escalar las tapias de los cementerios; desenterrar los cadáveres, abrirles pecho y vientre y mutilarles horriblemente las extrañas. Los que alguna vez hayais penetrado en estos lugares sagrados, firmamento del primor mental de la noche, alumbrados por la opaca luz de la luna, recordareis el extremecimiento religioso y pánico terror que se apodera del hombre cuerdo: de cada sepultura que pisa vé surgir el imponente espectro que resucita la memoria de séres perdidos, y comprendereis la profunda aberracion que supone el hecho de asaltar esas tapias, desenterrar los cadáveres con las propias uñas á falta de otros instrumentos, sepultar las manos en el interior de las estrañas de donde brotan sanies y pus, recibir la fétida emanacion de putrefactas vísceras, motivos todos sobrados para dejar yerto al hombre más impávido, y que, sin embargo, enardecian y alentaban al infeliz Bertrand, al extremo de desenterrar en una sola noche quince cadáveres. (Sensacion.) Terminada esta horrible operacion, caia fatigado, permanecia en una especie de letargo por breves momentos, y recobraba muy luego su calma.

Segun confesion propia, en las primeras ocasiones no satisfizo sus deseos venéreos; mas tarde se sintió ya impulsado á la profanacion genésica de los cadáveres.

Bertrand, señores, resistia el interrogatorio más prolijo, sin revelar perturbacion mental.

Recuerdo haber leido de una infeliz mujer de setenta y seis años, todavía mas decrépita, que su edad, que habia sido hallada cadáver en el campo, 
despues de horrible violacion, arrancada la mamila de un pecho de un bocado: ¿necesitariais conocer y examinar al autor para declararle loco, cualquiera que fuera su lucidez intelectual? Al que así no lo hiciera, no lo declararia yo loco, sino tonto (risas y aplausos), porque lejos de considerar como él, dicho atentado en el hombre cuerdo, digno del patíbulo, lo estimaria merecedor de la cruz de San Fernando, porque supone valor heróico. (Redoblan las risas.)

No habeis visto, señores, que unos hombres son más pendencieros que otros, luego hay inclinacion á la lucha; ved su congénere en la monomanía homicida. Se trata de un rico labrador que es feliz con su mujer é hijos, la muerte le arrebata á su compañera, y desde entonces se le vé triste: un dia siente la impulsion de matar á sus hijos, y retrocede aterrado ante la inmensidad del crímen, la idea le persigue incesantemente; pero él lucha y logra rechazarla, hasta que por fin, subyugado por tan horrible impulsion, se levanta tres noches consecutivas con deliberado intento de dar muerte á los hijos; la primera noche salta á la calle para librarse de sus impulsos que acrecen cada vez más; la segunda toma una navaja de afeitar y se pasea blandiendo el arma por lo largo de la habitacion lanzando feroz mirada á sus hijos; uno de ellos que lo advierte, se lo cuenta al siguiente dia á sus hermanos y les excita á huir de la casa: la tercera noche...; pero oigamos al más infeliz de los mortales, á este pobre desgraciado que refiere con exactitud cuanto aconteció, "salí y entré en la habitación varias veces, arreciando más y más mis impulsos; tomé una hazada que estaba cerca de la puerta, la volví á dejar creyendo que no me podia servir; entré en mi habitacion, y entonces me sentia aún más excitado; vuelvo á cojer la hazada, y penetro en la habitacion de mis hijos con una luz en la mano, y en la otra el horrible instrumento; dejo la luz junto á la cama de mi hijo, descorro las cortinas, y él no estaba; me dirijo á la cama de mis hijas, y las hallo medio dormidas; me acerco, y para tener mayor fuerza, apoyo el pié izquierdo en la silla que estaba al lado de la cama... y doy fuertes y repetidos golpes á la cabeza.» El cadáver de las muchachas ofreció en la autópsia numerosas fracturas de los huesos de la cabeza.

En este, como en otros muchos casos, se observa que el sentimiento ó instinto trastornado se dirije contra los séres amados, ó contra las personas que ocupan más su ánimo, como si la mente en el estado enfermo prosiguiera por el mismo camino que en el estado sano; es el torrente que se desborda, que obligado á seguir la misma corriente, arranca y arrastra al mar las plantas y árboles que ántes alimentaba con sus aguas; ¿puede dudarse de la locura de este padre, por más que relatara los hechos con exactitud detallada y coherentemente?

Nótase en la vida ordinaria, que hay sugetos con poco apego á la existencia, y de conformidad con nuestra doctrina, debe presentarse una monomanía suicida, y en efecto, señores, no ya los médicos, sino los profanos la reconocen y proclaman. $Y$ cuando éstas no tienen otra razon de ser que las 
demás, y cuando si registramos hechos evidentes de monomanías suicidas, no son menos claros y evidentes los de monomanías homicidas ¿no es verdad que hay motivo para dudar si el egoismo cierra el paso de entrada en la conciencia nuestra? El suicida atenta contra sí mismo, y todo el mundo observa los hechos, los interpreta sin prevencion y hace deducciones conformes á la verdad. El homicida atenta contra los demâs, y el egoismo de esta mísera sociedad previene el ánimo, los hechos se interpretan torcidamente, y el temor de mayores males les obliga á rechazar las monomanías homicidas: ¡torpe sociedad, parecida al buitre perseguido por el cazador, mete la cabeza en la arena y cree haber conjurado el peligro, cuando en realidad entonces sí que está á merced del cazador! Negando las monomanías homicidas permanece la sociedad ciega y maniatada ante el furor de estos desgraciados. (Sensacion.)

Más nótese, señores que el monomaniaco suicida puede ser homicida reflejamente, y lo es con frecuencia, y lo reconocieran á simple vista los tribunales, si su ánimo no estuviera preocupado.

Un jóven de diez y siete años, avanza precipitadamente hácia el carruaje que habia esperado con angustia durante largo tiempo, y que él creia condujera al Presidente de la república.

Observa rápidamente las personas que lo ocupan, mientras busca un objeto en el bolsillo de su paletó. No encontrando á quien esperaba, detiene su accion y se marcha: un policía, á quien como á muchos, habia chocado el aspecto y movimiento del jóven, se dirije hácia él para detenerle, y el jóven, en vez de huir, le sale al paso y le dice: «¿Estais aquí de servicio, no es verdad?» Pues bien, detenedme. Dos veces ha fallado mi golpe y es necesario concluir. He venido á matar al Presidente. (El suceso ocurrió en Paris el año $18 \ldots$...) Espero desde el medio dia, pero está visto que no he de realizar mi intento, porque al salir hace un momento el carruaje, cuando yo iba á disparar mi pistola, ya armada, noté que ocupaban el coche otras personas.» El polizonte le quita la pistola y le lleva á la prevencion. Este jóven era de ideas avanzadas, antecedentes morales desfavorables, tenia tédio á la vida, y poco apego al trabajo; habia intentdo suicidarse, poniéndose una pistola en la sien, y otra en la boca, y le habia faltado el coraje: continuando el disgusto por la vida, intenta realizar el suicidio en medio de la embriaguez, porque de otra suerte le faltaria valor; se emborracha en efecto, y como acontece muy á menudo, si el sugeto tiene cierto erotismo, se apodera el sentimiento genésico de la excitación, y en vez de atentar contra su vida, atenta contra el pudor de unas mujeres y produce un gran escándalo; es conducido á la prevencion: más tarde cree que su destino es matar al Presidente de la república, y hé ahí el conjunto de causas que determinan el atentado anterior. (Gaceta de los Tribunales.)

Otro ejemplo notable de monomanía suicida-homicida, es el que refiere Bierre de Boismont en estos ó parecidos términos: 
«Una noche del mes de Setiembre, del año 1851 , en tanto que los habitantes de Lyon asisten á un espectáculo interesante, se oye un gemido profundo, y un movimiento de horror se propaga entre los espectadores. Una jóven y bella esposa acaba de recibir tal herida en el cuello, que espira junto á su marido; el hombre que estaba sentado á su derecha, autor de la herida no la conocia: examinado el suceso, resulta, que este desgraciado tenia tédio á la vida, pero temeroso de no poderse arrepentir, pensó dar la muerte al emperador, después á un sacerdote, y abandonó uno y otro intento. En el mismo teatro habia pensado matar á alguno, más no hallaba oportunidad; por fin, se decidió á sacrificar á la jóven esposa referida.»

Si hubiese matado al emperador, de seguro hubiera sido considerado como asesino, pero mató á la jóven y es considerado loco. (Nutridos aplausos.)

¿No conoceis algun sugeto de carácter, suspicaz receloso? Pues á esta natural inclinación corresponde la monomanía de las persecuciones. El sugeto vive y está encargado á mi asistencia; comprendereis la razon por qué callo las circunstancias individuales y detalles numerosos que os pudiera referir; su inteligencia funciona con tal lucidez, que os sorprenderia; teme que se le ha de dar una muerte horrorosa, y deja correr la sangre de sus venas hasta el deliquio; coje un revolver un dia é intenta matar á una hermana suya; este ejemplo interesante, que no os puedo referir con detalles que acrecentaban su valor, prueba una verdad por mí observada tiempo há; tal es el de asociarse frecuentemente á la monomanía de las persecuciones, impulsos suicidas ú homicidas, ó ambos á la vez.

Un alto funcionario del Consejo de. Estado, padeció por espacio de doce años una monomanía de las persecuciones, tan circunscrita, que desempeñaba su cargo sin ser conocida de sus compañeros, y puesta en duda por su propia familia; fuí llamado á visitarle, y aconsejé que le llevaran á un manicomio, porque tenia pleno convencimiento de que acabaria por suicidarse. «Cá, doctor, me arguye su padre; esa es la historia de doce años de tentativas.» «Pues esa, le contesté, es la historia de todos los suicidas por reflexión.» «Conste que yo no le visito»; á los quince dias próximamente, al regresar de la oficina, entra en el portal de su casa y se dispara un tiro que se atraviesa el corazon.

¿No conoceis personas dadas á repetir todo lo que les impresiona, que si van al teatro vuelven á casa y declaman, que si al circo dan saltos y piruetas? Pues á esta inclinacion corresponde otra monomanía, en que el ánimo es arrastrado fatalmente, y contra las protestas de su inteligencia y sentimientos, á ejecutar el mismo atentado que las conmovió. Escuchad un caso reciente, actual.

Unos tres meses y medio apenas hace, se presentó en mi consulta una mujer de unos veintisiete años de edad, de temperamento nervioso, demacrada, morena, pálida, cuyo semblante expresaba la más profunda melancolía; os aseguro que la mera contemplacion de aquella fisonomía exhuberante de 
pena y de dolor, cautivó mi ánimo desde los primeros momentos, y tan suspenso me tuvo durante su larga relación, que la recuerdo perfectamente, aun en sus detalles más mínimos; pero tambien aquí el secreto médico me impone cierto silencio. ¡Ah! si nos fuera dado revelar todas las pequeñas perturbaciones que se nos confian en el confesionario médico!. ¡Si los jurisconsultos estuvieran presentes y sin ser vistos en nuestra consulta, otra fuera su doctrina sobre el entendimiento humano! ¡Entonces notarian con sorpresa que hay muchos locos á quienes la sociedad tiene por cuerdos!

Más volvamos a nuestra jóven artesana, señor, me digo, acababa de leer en un periódico la acusacion fiscal de Angel Ursúa, y me sentí con malestar y aturdida; cuando llegó del trabajo mi marido nos pusimos á la mesa para comer, y yo no tenia apetito; mi marido me insta una y otra vez y yo intento complacerle, pero todo era en vano, no podia pasar siquiera el agua, tenia como un nudo que me cerraba la garganta. Insiste él en que coma, y me siento nuevamente; me fijo en el cuchillo y me levanto lanzando un grito de horror, ¡se me habia ocurrido dar á mi esposo la misma muerte que Angel Ursúa habia dado á la viuda del general Pierrard! desde entonces, señor, ese deseo me persigue constantemente noche y dia, á todas horas.» Sintiendo flaquear su ánimo le refiere su desgracia á la hermana mayor que la acompañaba, y ésta se promete arrancarle la mala idea con sus consejos y cuidados, ¡vano intento! no se contiene el desbordado instinto con tal débil refuerzo; crece cada vez más el furioso impulso, y de comun acuerdo las dos hermanas, deciden contárselo al marido; éste, lleno de bondad, multiplica desde entonces sus cuidados habituales para con su esposa, sin advertir, desgraciado, que á medida que aumentan sus desvelos y ternuras, acrece la sangrienta lucha del pertináz impulso, y la inteligencia y demás sentimientos no heridos: ¡cuanto más embellece á la víctima una conducta nobilísima, más rudo es el combate! Por fin, señores, imagináos á esa desgraciada constantemente perseguida por $\tan$ horroroso impulso; en casa, en la calle, en paseo, durante la vigilia, en el sueño, y comprendereis los sufrimientos de su transido corazon. $\mathrm{La}$ inapetencia, el insomnio, las angustias que devoraban su alma, acaban por postrar su cuerpo, y á medida que enflaquecia su organismo, desfallecia su fuerza de resistencia...; pues figuraos que esta mujer infortunada tras largos dias y pruebas infinitas de tierna solicitud y cariñoso cuidado de su idolatrado esposo, á quien ama con delirio, se sienta con él en la mesa, vé el cuchillo y experimenta un exttemecimiento, intenta levantarse y vé bañada en sangre la víctima de Angel Ursúa; esa imágen enardece su cerebro; empuña el cuchillo, y rugiendo como una hiena, levanta el brazo para clavar el arma en el pecho de su marido, y cae presa de mortal angustia en medio de horribles convulsiones, exclamando: «ihuye, infeliz, voy á matarte!» ¿Os imaginais, señores, los horrorosos sufrimientos que experimentaria esta desgraciada al verse impelida á matar á su esposo contra la protesta enérgica de toda su inteligencia y todos sus sentimientos? ¡Sangrientas y feroces son las luchas 
que el hombre libra en las calles y en los campos de batalla, pero mil veces más sangrientos y feroces son los combates que el hombre riñe en el interior de su corazon, en el fondo de su conciencia! (Bien, bien.)

La enferma vive y esta circunstancia me obliga á omitir interesantísimos detalles y alterar ciertos accidentes.

Libre la inteligencia de esta infeliz, y emancipada del poder de un impulso, ella misma discurre medios para no consumar el atentado; como un ciudadano francés que sentó plaza y pasó á Crimea para librarse de dar muerte á su querida madre, y que habiendo regresado al hogar paterno en donde se avivaron sus deseos, sentó nuevamente plaza y vino á nuestra bella península, á conquistar á España, mejor dijéramos á presenciar la más grande epopeya del amor pátrio; y sin embargo, no logró verse libre de tan crueles impulsos. Otro caso análogo cita Bonnuci, de un aldeano que habiendo sentido enérgicas impulsiones de matar á su mujer, con la misma cuchilla con que iba á realizarlo, de un tajo se cortó el brazo para no llevar á efecto el atentado.

Mas no fien, señores, ni en el poder directivo de la inteligencia ni en la fuerza cohibitiva de los sentimientos é instintos sanos. Las más de las veces sucumben al sentimiento enfermo, y son arrastrados á la ejecucion del homicidio.

La lucha de los sentimientos, la protesta de la inteligencia, la designación de víctima, etc. Todos son accidentes que penden de las condiciones individuales, $\mathrm{y}$ otras circunstancias que en nada alteran la irresponsabilidad del sugeto.

Yo pretendia llamar vuestra atencion hácia el singular fenómeno que todos presenciamos, aunque no paran mientes en ello: tal es, de que la locura invade cada vez más el terreno que por abuso de demarcación se le asignaba al crímen y á la santidad.

¿Quién habrá hojeado los anales de la Inquisición, sin sacar de ellos la convicción más profunda de que aquellas víctimas fueron sacrificadas por la barbarie de los tiempos y las preocupaciones de los hombres? ¿Hay hoy algun magistrado que condenara al patíbulo á un infeliz, porque azotare la imágen del Redentor, porque se proclamare nuevo Mesías ó segunda persona de la Santísima Trinidad? Pues recordad que en época no muy lejana, los demoniolatrax expiaban en el patíbulo el crimen de estar enfermos. ¡A cuántas consideraciones no se presta este fenómeno!

Demostremos, señores, la perturbacion de algunos supuestos criminales que los magistrados les librarán y sentirán la inefable dicha que experimenta el hombre virtuoso que le arrebata el verdugo una víctima, y le entrega á la beneficencia para que la ampare y al médico para que le cure.

Yo, señores, por último, y en calidad de suprema razon, me proponia citaros una estadística de Wingtimier ${ }^{1}$, médico de las prisiones de Rouen, cuya

${ }^{1}$ De 262 presos, en que se sospechaba alteracion mental, 4 murieron en la prision antes de sufrir condena; 176 fueron reconocidos como locos hasta por los jueces; y de los 
fuerza de convicción es tal, y cuya elocuencia tanta, que acabará de conquistarnos los pocos entendimientos que permanecen indecisos, sin pasarse á nuestro campo.

Señores, yo os pensaba referir multitud de hechos análogos; esto es, de monomanías impulsivas sin perturbación de la inteligencia, ó con leve é imperceptible delirio, pero hemos traspuesto la hora reglamentaria, y no me atrevo á continuar. (Muchas voces, sí, sí.) No abusaré de vuestra inagotable bondad para conmigo, pero sabed que al divulgarse el ruidoso asesinato de una niña, sin motivo, realizado por Enriqueta Cornier, muchas mujeres se sintieron con deseo de matar niños; en Paris, segun afirma Morel, no se trataba en 1825 más que del asesinato causado por la jóven Cornier, y en aquel tiempo los manicomios recibían muchas mujeres afectadas de la misma tendencia homicida. Yo pretendia citaros el hecho de una jóven que desde que presenció en Dresde el suplicio de una mujer condenada por asesinato, subyugada por el imponente aspecto del patíbulo, soñaba como la mayor felicidad de la vida poder terminar sus dias de un modo igual; me refiero á Guillerma Strohm (citada en los Anales médico-psicológicos, 1851), que dio muerte á Sofía Hujel, sin más razon ni motivo que su sinrazon y el ánsia de morir en el patíbulo.

Yo queria despues de daros clínica oral, demostrar el enlace, relacion y razon de causalidad que une los suicidios, y esos otros atentados que tanto preocupan la opinion pública.

Yo queria probar que la interesante y conmovedora relacion de un atentado, la augusta suspension del ánimo, cuando vá á tener lugar una ejecucion, las escenas de la capilla, referidas con vivos colores; el tropel de gentes que se precipita para llenar la carrera del desgraciado; los diferentes movimientos pasionales que agitan y conmueven á la multitud; la presencia del reo ó del enajenado en lo alto del patíbulo, soliviantan el ánimo movedizo de ciertos desgraciados y los impele á realizar esos atentados que estremecen la conciencia humana.

Yo os queria decir, ó que vosotros lo dedujérais, tras de la exposicion de los hechos, que si despues de un suicidio que ha interesado la opinion pública, nótase mayor frecuencia de estos mismos atentados, no busqueis otro motivo ni razon causal, que la dibujacion hecha con vivos colores, que la interesante relacion de ellos.

Yo os queria probar, sin razonamientos por parte mia, con solo la exposicion de los hechos, que la ejemplaridad de un castigo, no intimida ni ejerce accion alguna sobre la conciencia del enajenado, ántes al contrario, que de la

82 condenados sin ó contra la opinion del médico; 6 lo fueron por crímenes, y de ellos uno, despues de su locura, callo en un estado de estupidez (demencia): otro fué conducido loco á Brest; el quinto llegó al último grado de demencia, y el sesto no hubo tiempo de reconocerle, porque murió muy pronto.

Con motivo de las reflexiones á que se presta esta estadística, pensaba consagrar un cariñoso recuerdo á mi venerable maestro el Dr. Mata. 
relacion del suceso, ardientes comentarios, apasionadas apreciaciones, y enormidad de la pena, saltan las chispas que prenden fuego á las exaltadas imaginaciones.

¡Ah, señores! Yo os pregunto, á los que no cultivais las ciencias médicas, si teniendo los frenópatas á cada paso hechos como los referidos, y otros mil que pudiera citar, debemos ni podemos ménos de admitir las monomanías impulsivas, esto es, sin lesión de la inteligencia, que han producido trastorno de ella, y ¡todavía se nos acusa de que amparamos el crímen, de que hacemos causa comun con los asesinos! Protestamos con toda la energía de nuestra alma contra el crímen, y sino nos abrasamos en colérica indignacion al oir tales injurias, es porque su asquerosa repugnancia no nos inspira más que desprecio.

Señores, seguid impávidos, no revelando otras doctrinas que las que profese vuestra honrada conciencia, y cuando fuereis llamados á ejercerlas como peritos, aplicadlas con rigor, sin que os intimiden las torpes amenazas de imbécil muchedumbre.

Cerrad vuestros oidos á las instigaciones de la compasion, y mostráos igualmente sordos á la amenaza de ulteriores consecuencias. La declaracion de enagenado que recayera sobre un mísero criminal, nos despojaria de la autoridad moral que ha de tener nuestro dictámen, para arrancar mañana de manos del verdugo al inocente loco. Fiat justitia et ruat celum.

Cuando fuereis llamados á informar ante los tribunales, eleváos á la alteza de vuestra sublime mision; más que á la humanidad, más que á su familia, y más que á sí mismo, en casos tales, si antagonismo existiera, se debe el médico á la ciencia que cultiva.

Yo por mí he de deciros, que si supiera decretar mi propio infortunio, la desgracia de mi familia y la ruina de mi pátria, con declarar loco al que no lo es, ó viceversa, hundiérame, sepultara á mi familia, y cambiara los destinos de mi pátria, antes que faltar á la verdad. ¿La humanidad entera no justificará con su salvacion la prevaricacion de un médico! ¡Decir que nosotros alentamos á los criminales! ¡Ah! (Grandes aplausos.) Si no fuera impropio de este lugar, é indigno de nosotros mismos, yo calificaria cual se merece esa asquerosa provocacion. Los que arrastran al crímen más de un entendimiento débil, son los que piensan aterrarle con la inconcebible desproporcion de la pena; los que levantan el imponente aspecto del patíbulo, que tiene la fuerza y accion vertiginosa de las grandes corrientes, el atractivo de los profundos abismos.

El loco es irresponsabie; su ejecucion un asesinato legal; ila personalidad del loco es sagrada para Dios, y debe ser inviolable para los hombres! y $j$ mirad que por uno de esos misterios inescrutables de la Providencia, la sangre de un loco que se vierte en el patíbulo enfurece á otro insensato y le convierte en su vengador! (Prolongados y repetidos aplausos.) 
CRITICA DE LIBROS 